\title{
Analisis Kerentanan Pesisir di Kabupaten Pesisir Selatan Provinsi Sumatera Barat
}

\author{
Coastal Vulnerability Analysis in Pesisir Selatan Regency West Sumatera Province \\ Yoga Novriadi $^{1^{*}}$, Mubarak $^{1}$, Elizal $^{1}$ \\ ${ }^{1}$ Jurusan Ilmu Kelautan, Fakultas Perikanan dan Kelautan, Universitas Riau \\ Kampus Bina Widya Jl. HR. Soebrantas Km 12.5, Pekanbaru, 28293 \\ email: ynovriadi@gmail.com
}

(Received: 21 November 2021; Accepted: 25 Februari 2022)

\begin{abstract}
ABSTRAK
Penelitian dilakukan di Kabupaten Pesisir Selatan Provinsi Sumatera barat pada bulan Oktober - November 2019. Tujuan dari penelitian ini adalah untuk mengetahui perubahan garis pantai dan tingkat kerentanan pesisir. Data primer diperoleh dari pengamatan lapangan dan data sekunder dari sumber terkait. Hasil penelitian menunjukkan wilayah ini mengalami akresi yang berkisar (1->2,1m/th) dan erosi (-1-<-2 m/th). Indeks kerentanan pesisir umumnya sangat rendah, namun di beberapa titik mengalami kerentanan sangat tinggi karena sangat terpapar terhadap gelombang dan adanya aktivitas antropogenik yang tinggi, sehingga mengakibatkan terjadinya erosi hingga $65 \%$ selama 10 tahun terakhir.
\end{abstract}

Kata Kunci: Pesisir Selatan, Garis Pantai, Kerentanan

\begin{abstract}
The research was conducted in Pesisir Selatan Regency West Sumatra Province in October November 2019. The aim of the study is to determine coastline changes and coastal vulnerability index. Primary data were obtained from field observations and secondary data from related sources. The results of this research showed the area was changed due to the occurance of accretion nearly $(1->2.1 \mathrm{~m} /$ year) and abbration about $(-1-<-2 \mathrm{~m} /$ year). The coastal vulnerability index is generally very low, but at some points the vulnerability had an exaggerated value because it is fully exposed to waves and high anthropogenic activities, resulting in abbration of up to $65 \%$ over the last 10 years.
\end{abstract}

Keyword: Pesisir Selatan, Coastline, Vulnerability

\section{Pendahuluan}

Wilayah pesisir merupakan kawasan peralihan antara darat dan laut yang secara fisik merupakan kawasan yang sempit. Wilayah pesisir kaya akan potensi sumbar daya hayati maupun non hayati, baik yang berada di mintakat daratan maupun perairannya. Aktivitas ekonomi dan tekanan penduduk dalam rangka peningkatan kesejahteraan akan memanfaatkan ruang yang tersedia, termasuk pesisir sebagai wilayah yang relatif mudah dijangkau sebagai alat pengembangan aktivitas manusia (Marfai et al., 2008). Selain itu, lingkungan pesisir juga dapat berubah secara konstan karena gelombang, angina, arus samudera dan proses antroposentris (Alexandrakis et al.,2015).

BNPB (2019) menyatakan bahwa Kabupaten Pesisir Selatan berada di kelas bahaya tingkat tinggi terhadap tsunami, meskipun demikian Kabupaten Pesisir Selatan telah dikembangkan sebagai objek wisata bahari sejak tahun 2002 melalui Dinas Pariwisata Kabupaten Pesisir Selatan (Fuadi dan Yoswaty, 2016) sehingga penggunaan lahan akan meningkat dari tahun sebelumnya. Hal ini akan berdampak meningkatkan resiko kerentanan pesisir, maka dari itu sangat penting dilakukannya penelitian mengenai kerentanan pesisir. 


\section{Metode Penelitian}

\subsection{Waktu dan Tempat}

Penelitian ini dilakukan di Kabupaten Pesisir Selatan pada bulan Oktober November 2019.

\subsection{Metode Penelitian}

Metode yang digunakan dalam penelitian ini adalah metode survey yang dibagi dalam tiga tahapan yaitu pengumpulan data, pengolahan data dan analisis kerentanan pesisir. Pengambilan data primer dilakukan dengan pengamatan langsung di lapangan (in situ) dan data sekunder diperoleh dari sumber terkait. Pengolahan data menggunakan teknik pemetaan yang disebut pendekatan Smartline (Sharples et al., 2009) dan analisis data menggunakan rumus CVI (Gornitz et al., 1991). Parameter yang digunakan dalam analisis kerentanan pesisir pada Tabel 1 .

\section{Tabel 1. Parameter fisik kerentanan pesisir}

\begin{tabular}{|c|c|c|c|c|c|c|}
\hline \multirow[t]{4}{*}{ No } & \multirow[t]{4}{*}{ Parameter } & \multicolumn{5}{|c|}{ Penilaian } \\
\hline & & Sangat & Rendah & Sedang & Tinggi & Sangat \\
\hline & & Rendah & & & & Tingggi \\
\hline & & 1 & 2 & 3 & 4 & 5 \\
\hline 1 & $\begin{array}{l}\text { Material Penyusun } \\
\text { Pantai }\end{array}$ & Ice & Coral & Hard Rock & Soft Rock & Soft Sediment \\
\hline 2 & Geomorfologi & Tebing & $\begin{array}{l}\text { Talus, Stable } \\
\text { Beach With } \\
\text { Vegetaion }\end{array}$ & $\begin{array}{l}\text { Talus, Stable } \\
\text { Beach Without } \\
\text { Vegetation }\end{array}$ & Beach & $\begin{array}{l}\text { Delta, Rawa, } \\
\text { Dune } \\
\text { (gundukan } \\
\text { pasir) }\end{array}$ \\
\hline 3 & $\operatorname{DEM}(\mathrm{m})$ & $>25$ & $17-24$ & $11-17$ & $4-10$ & $0-3$ \\
\hline 4 & $\begin{array}{l}\text { Paparan Terhadap } \\
\text { Gelombang }\end{array}$ & & Terlindung & Semi terpapar & Terpapar & $\begin{array}{l}\text { Terpapar } \\
\text { seluruhnya }\end{array}$ \\
\hline 5 & Kemiringan (\%) & $1-13$ & $14-20$ & $21-28$ & $29-35$ & $>36$ \\
\hline 6 & Tinggi Gelombang & $<0,5$ & $0,5-1$ & $1-1,5$ & $1,5-2$ & $>2$ \\
\hline 7 & Fitur Berm & $\begin{array}{l}\text { Hutan, } \\
\text { Tambak, } \\
\text { Rawa }\end{array}$ & $\begin{array}{l}\text { Daerah } \\
\text { Pedesaan }\end{array}$ & $\begin{array}{l}\text { Mixed Rural } \\
\text { Zone }\end{array}$ & $\begin{array}{l}\text { Urban (kota) } \\
\text { Zone }\end{array}$ & $\begin{array}{l}\text { Mixed Urban } \\
\text { (Industri, } \\
\text { Sekolah dll) }\end{array}$ \\
\hline 8 & Ukuran Butir & Sangat Halus & Halus & Sedang & Kasar & Sangat Kasar \\
\hline 9 & Range Pasut (m) & $<1$ & $1-1,9$ & $2-4$ & $4,1-6$ & $>6$ \\
\hline 10 & $\begin{array}{l}\text { Jarak garis pantai } \\
\text { dengan objek yang } \\
\text { rentan }(\mathrm{m})\end{array}$ & $>61$ & $31-60$ & $21-30$ & $11-20$ & $0-10$ \\
\hline 11 & Ketinggian Berm & $>30.1$ & $20,1-30$ & $10,1-20$ & $5,1-10$ & $0-5$ \\
\hline 12 & Fitur Beachface & $\begin{array}{l}\text { Pelindung } \\
\text { Pantai }\end{array}$ & Sabuk Hijau & & & Lahan Kosong \\
\hline 13 & $\begin{array}{l}\text { Perubahan Garis } \\
\text { Pantai }(\mathrm{m} / \mathrm{t})\end{array}$ & $\begin{array}{l}\text { Akresi tinggi } \\
(>2,1)\end{array}$ & $\begin{array}{l}\text { Akresi rendah } \\
(1-2)\end{array}$ & Stabil $(-1-+1)$ & $\begin{array}{l}\text { Erosi Sedang } \\
(-1-+2)\end{array}$ & $\begin{array}{l}\text { Erosi Tinggi } \\
(<-2)\end{array}$ \\
\hline 14 & Tata guna lahan & $\begin{array}{l}\text { Protected } \\
\text { Area }\end{array}$ & Unclaimed & Settlement & Industrial & Agriculture \\
\hline 15 & $\begin{array}{l}\text { Kondisi Pelindung } \\
\text { pantai }\end{array}$ & Bagus & & Perlu Perbaikan & & $\begin{array}{l}\text { Tidak Ada } \\
\text { Pelindung } \\
\text { Pantai }\end{array}$ \\
\hline
\end{tabular}

\subsection{Prosedur Penelitian}

\subsubsection{Pengamatan Lapangan dan Ground Check}

Pengambilan data material penyusun pantai, geomorfologi, paparan terhadap gelombang, fitur berm, ketinggian berm, fitur beachface, tata guna lahan dan kondisi pelindung pantai dilakukan secara visual di lapangan dengan jarak antar titik pengamatan $\pm 1 \mathrm{~km}$. Kemiringan pantai diukur dengan waterpass, ukuran butir diukur dengan skala Wenworth, dan jarak garis pantai ke objek yang rentan diukur dengan meteran. Data elevasi dari situs Earth Explorer USGS (https://earthexplorer.usgs.gov), tinggi gelombang signifikan dari situs BMKG Ocean Forecast System (https://petamaritim.bmkg.go.id/ofs/\#), data pasang surut air laut dari www.Tides. big.go.id, dan perubahan garis pantai dari perbandingan nilai citra Landsat 5 tahun 2008 dan citra Landsat 8 tahun 2018 dengan resolusi $30 \mathrm{~m}$.

\subsubsection{Analisis Spasial}

Analisis spasial dilakukan dengan menggunakan 15 parameter fisik kerentanan 
pesisir. Penilaian tingkat kerentanan dihitung menggunakan persamaan CVI (Gornitzs et al., 1991):

$$
\mathrm{CVI}=\frac{\sqrt{x 1 * x 2 * x 3 * \ldots * x n}}{n}
$$

Keterangan:

$\mathrm{x}=$ Nilai setiap parameter $\mathrm{n}=$ Jumlah total parameter

\section{Hasil dan Pembahasan \\ 3.1. Parameter Kerentanan Pesisir}

Dari pengolahan data primer dan data sekunder, maka didapatkan nilai tiap parameter kerentanan pesisir pada Tabel 2.

Tabel 2. Nilai setiap parameter kerentanan pesisir

\begin{tabular}{llccccc}
\hline \multirow{2}{*}{ No } & \multicolumn{1}{c}{ Parameter } & \multicolumn{5}{c}{ Nilai Tingkat Kerentanan Pesisir (\%) } \\
\cline { 3 - 6 } & Mangat Rendah & Rendah & Sedang & Tinggi & Sangat Tinggi \\
\hline 1 & Material penyusun pantai & - & 0.9 & 0.8 & - & 98.3 \\
2 & Geomorfologi & 1.1 & - & - & 98.9 & - \\
3 & DEM & 1.9 & 3 & 41.1 & 43.5 & 10.5 \\
4 & Paparan terhadap gelombang & - & 4.4 & 5.4 & 28.9 & 61.3 \\
5 & Slope & 100 & - & - & - & - \\
6 & Tinggi gelombang & 59.4 & 40.6 & - & - & - \\
7 & Fitur berm & 57.3 & 35.07 & 0.31 & 0.48 & 6.82 \\
8 & Ukuran butir & - & 69.30 & 19.5 & 11.2 & - \\
9 & Tunggang pasang surut & & 100 & - & - & - \\
10 & Jarak garis pantai dengan & 58.8 & 1.3 & 4.1 & 7.6 & 28.2 \\
11 & objek rentan & & & & \\
12 & Ketinggian berm & - & 0.6 & 7.0 & - & 92.3 \\
13 & Perubahan garis pantai & 6.8 & 17.9 & - & - & 75.3 \\
14 & Tataguna lahan & 14.1 & 8.9 & 11.8 & 6.4 & 58.7 \\
15 & Kondisi pelindung pantai & - & 24.8 & 39.1 & 7.8 & 28.3 \\
\hline
\end{tabular}

Secara umum geomorfologi pantai Kabupaten Pesisir Selatan berbentuk beach, bentuk cliff/tebing terdapat di Kecamatan Koto XI Tarusan, IV Jurai dan Batang Kapas. Geomorfologi beach berada di tingkat kerantanan tinggi (Jadidi et al., 2013) dengan material penyusun pantai soft sediment $98 \%$, $1 \%$ coral, dan $1 \%$ hard rock. Hal ini karena batuan induk dari daratan adalah batuan gunung api oligo-miosen (tomp) berupa batuan sedimen dan batuan gunung api terdiri dari lava, breksi, breksi tuf, tuf hablur, ignimbrite dan tuf sela berupa pasir dan kerikil (Rosidi et al., 1996). Kabupaten Pesisir Selatan memiliki lingkungan pengendapan transisional yaitu interaksi antara sungai dan laut (Rozamuri dan Hidayat, 2016) sehingga memiliki material soft sediment yang berukuran halus. Pengukuran ukuran butir menggunakan skala Wenworths menunjukkan $69 \%$ pasir berukuran halus, yaitu di Kecamatan Batang Kapas, Sutera, Lengayang, Ranah Pesisir, Linggo Sari, Pancung Soal dan Lunang Silaut, kemudian $20 \%$ berukuran sedang, dan $11 \%$ lainnya berukuran kasar di Kecamatan Koto XI Tarusan. Peta sebaran material penyusun pantai dapat dilihat pada Gambar 1.

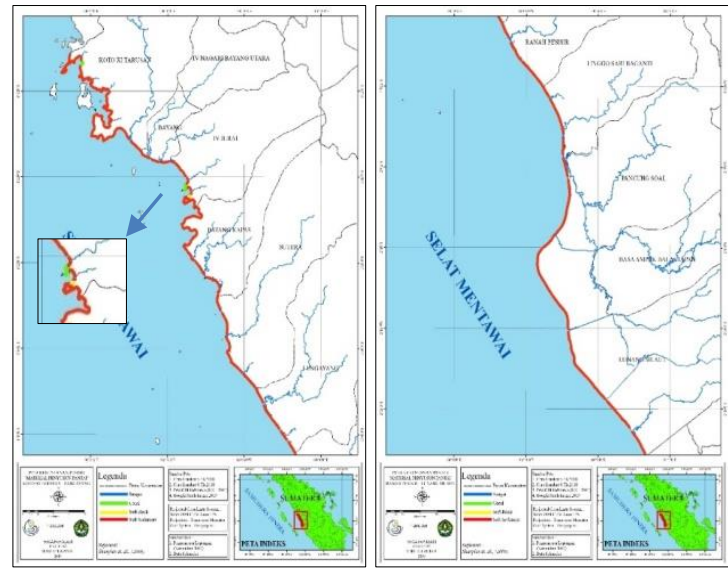

Gambar 1. Peta material penyusun pantai

Nilai DEM Kabupaten Pesisir Selatan didominasi $4-10 \mathrm{~m}$ sebanyak $44 \%, 11-17 \mathrm{~m}$ sebanyak 41\%, $0-3 \mathrm{~m}$ sebanyak $11 \%$ dan sisanya bernilai $17-24 \mathrm{~m}$ hingga $>25 \mathrm{~m}$ (Gambar 2). Dhiauddin et al. (2017) menyatakan kemiringan pantai akan berpengaruh terhadap tingkat terancamnya wilayah pesisir dari kenaikan muka laut, 
selain itu kemiringan pantai juga berhubungan dengan energi gelombang.

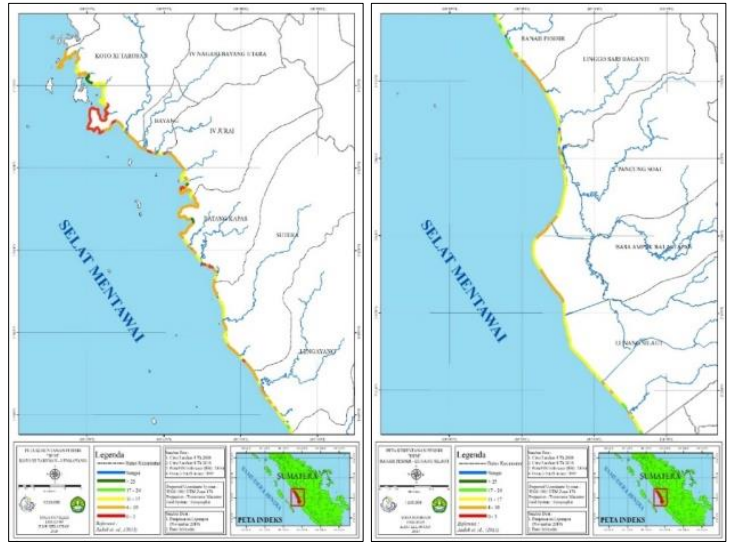

Gambar 2. Peta nilai DEM

Tinggi gelombang signifikan $<0.5 \mathrm{~m}$ di Koto XI Tarusan hingga Lengayang dan 0.5 $1 \mathrm{~m}$ di Ranah Pesisir hingga Lunang Silaut. Grafik tunggang pasang surut dapat dilihat pada Gambar 3.

Tabel 2. Nilai Laju Perubahan Garis Pantai

\begin{tabular}{lllllllllll}
\hline Lokasi & $\begin{array}{l}\text { Koto XI } \\
\text { Tarusan }\end{array}$ & Bayang & $\begin{array}{l}\text { IV } \\
\text { Jurai }\end{array}$ & $\begin{array}{l}\text { Batang } \\
\text { kapas }\end{array}$ & Sutera & $\begin{array}{l}\text { Lenga- } \\
\text { yang }\end{array}$ & $\begin{array}{l}\text { Ranah } \\
\text { Pesisir }\end{array}$ & $\begin{array}{l}\text { Linggo- } \\
\text { Sari }\end{array}$ & $\begin{array}{l}\text { Pancung } \\
\text { Soal }\end{array}$ & $\begin{array}{l}\text { Lunang } \\
\text { Silaut }\end{array}$ \\
\hline $\begin{array}{l}\text { Akresi } \\
\text { tertinggi } \\
\text { (m/tahun) }\end{array}$ & 82,29 & 5,56 & 2,91 & 3,32 & 2,35 & 45,28 & $-0,6$ & 1,93 & 4,66 & 4,1 \\
$\begin{array}{l}\text { Erosi } \\
\text { tertinggi } \\
(m / \text { tahun })\end{array}$ & $-12,4$ & $-2,52$ & $-8,17$ & $-3,33$ & $-13,93$ & $-16,32$ & $-7,1$ & $-10,34$ & $-9,7$ & $-9,12$ \\
\hline
\end{tabular}
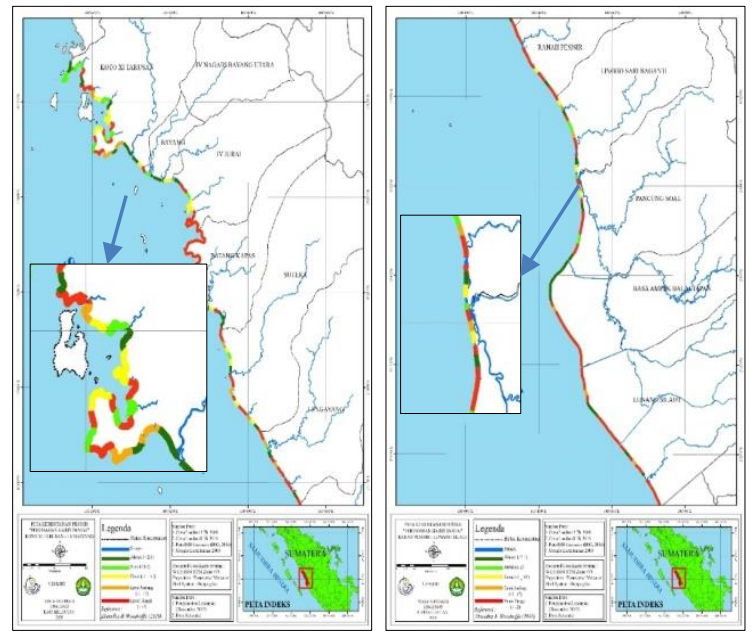

Gambar 4. Peta laju perubahan garis pantai

Fitur beachface Kabupaten Pesisir Selatan sebesar $75 \%$ merupakan lahan kosong, 18\% memiliki sabuk hijau dan $6 \%$ memiliki bangunan pelindung pantai. Tata

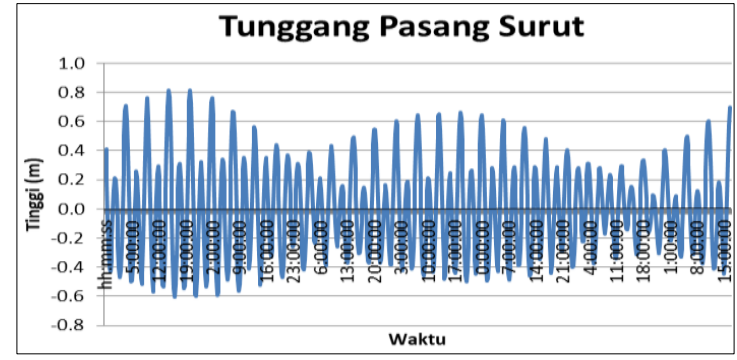

Gambar 3. Pasang Surut

Paparan bersifat fully exposed $61 \%, 29 \%$ exposed, 6\% semi sheltered dan $4 \%$ sheltered. Kerentanan tertinggi fully exposed dan kerentanan terendah sheltered (Gornitzs et al., 1992). Karena itu, wilayah ini dominan mengalami erosi, $59 \%$ erosi sangat tinggi, $6 \%$ erosi sedang, kemudian akresi tinggi 4\%, akresi sedang 9\% dan 12\% kondisi stabil (Gambar 4). Di Kecamatan IV Jurai dan Batang Kapas terjadi pembukaan lahan untuk objek wisata dan tambak, di Kecamatan Linggo Sari Baganti hingga Lunang Silaut digunakan sebagai kebun sawit. Nilai laju perubahan garis pantai (Tabel 3) 
unclaimed, 28\% area industrial dan 8\% kawasan agrikultur (Gambar 6).

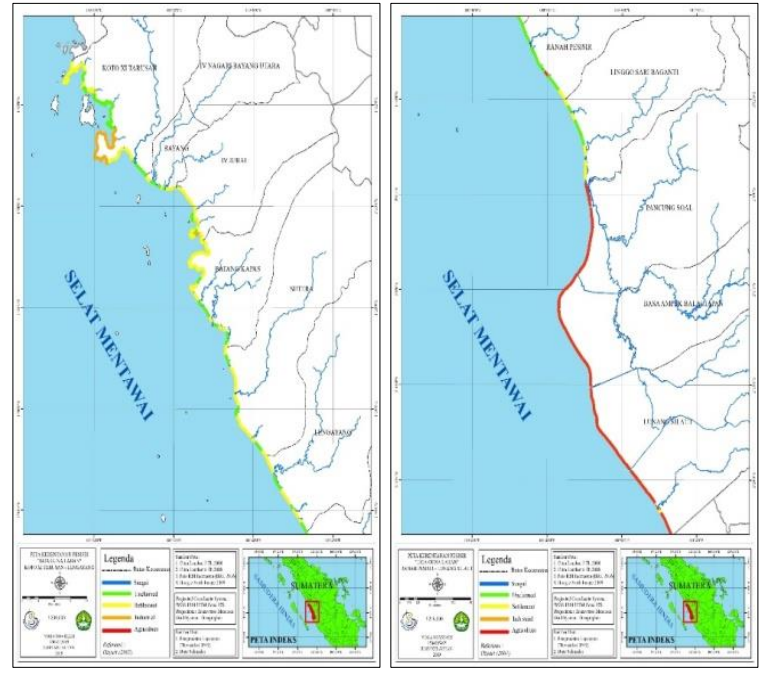

Gambar 6. Tata guna lahan

Jarak garis pantai ke objek yang rentan di wilayah pesisir Kabupaten Pesisir Selatan didominasi oleh jarak >61 m sebanyak 59\% yaitu di Kecamatan Koto XI Tarusan, Pancung Soal, dan Lunang Silaut, jarak 31-60 $\mathrm{m}$ sebesar 1\%, jarak 21-30 m sebesar $4 \%$, jarak 11-20 m sebesar $8 \%$ dan $28 \%$ lainnya merupakan wilayah yang memiliki jarak ke objek yang rentan sebesar $0-10 \quad \mathrm{~m}$ di Kecamatan IV Jurai dan Batang Kapas. Selain faktor alam, penggunaan lahan akan berpengaruh terhadap kondisi pelindung pantai dan berdampak terhadap kerentanan pesisir. Sebesar 85\% wilayah pesisir Kabupaten Pesisir Selatan tidak memiliki pelindung pantai, $3 \%$ kondisi pelindung pantai yang perlu perbaikan, sedangkan pelindung pantai dengan kondisi masih bagus hanya sebesar $12 \%$.
Perhitungan nilai indeks kerentanan pesisir di Kabupaten Pesisir Selatan menggunakan formula CVI yaitu sebesar 16,97-2309,40 dengan tingkatannya sebagai berikut :

$\begin{array}{lll}\text { Sangat Rendah } & : & \leq 458,48 \\ \text { Rendah } & : & 458,48<\mathrm{CVI} \leq 916,97 \\ \text { Sedang } & : & 916,97<\mathrm{CVI} \leq 1375,45 \\ \text { Tinggi } & : & 1375,45<\mathrm{CVI} \leq 1833,94 \\ \text { Sangat Tinggi } & : & >1833,94\end{array}$

Nilai CVI tersebut diinterpretasikan ke bentuk peta kerentanan pesisir yang dapat dilihat pada Gambar 7.
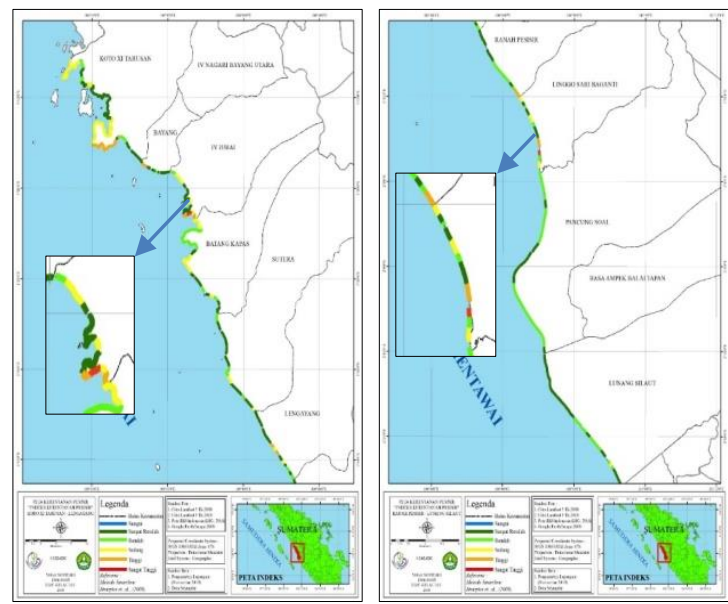

\section{Gambar 7. Kerentanan Pesisir Kabupaten Pesisir Selatan}

Kabupaten Pesisir Selatan memiliki kerentanan sangat rendah sebesar 44,5\%, tingkat kerentanan rendah $27,9 \%$, tingkat kerentanan sedang 19,5\%, tingkat kerentanan tinggi $6,9 \%$ dan tingkat kerentanan sangat tinggi $0,8 \%$ yang terjadi di Kecamatan IV Jurai dan Linggo Sari Baganti (Tabel 4)

Tabel 3. Persentase nilai kerentanan pesisir Kabupaten Pesisir Selatan

\begin{tabular}{|c|c|c|c|c|c|c|c|}
\hline \multicolumn{8}{|c|}{ Indeks Kerentanan Pesisir (CVI) } \\
\hline \multicolumn{2}{|c|}{ Sangat Rendah } & \multicolumn{2}{|c|}{ Rendah } & \multicolumn{2}{|c|}{ Sedang } & Tinggi & Sangat Tinggi \\
\hline Panjang (m) & $\%$ & $\begin{array}{l}\text { Panjang } \\
\text { (m) }\end{array}$ & $\%$ & $\begin{array}{l}\text { Panjang } \\
\text { (m) }\end{array}$ & $\%$ & $\begin{array}{l}\text { Panjang } \\
\text { (m) }\end{array}$ & $\begin{array}{l}\text { Panjang \% } \\
\text { (m) }\end{array}$ \\
\hline 101611.25 & 44.9 & 63098.65 & 27.9 & 44250.03 & 19.5 & $15523.33 \quad 6.9$ & $1904.34 \quad 0.8$ \\
\hline
\end{tabular}

\section{Kesimpulan dan Saran}

Secara umum Kabupaten Pesisir Selatan didominasi oleh material soft sediment dengan geomorfologi berbentuk beach, namun Kabupaten Pesisir Selatan tidak memiliki ombak dan tunggang pasang surut yang terlalu tinggi sehingga menjadikan wilayah pesisir tidak terlalu rentan dan berada di tingkat kerentanan sangat rendah. Beberapa kawasan pesisir yang mengalami kerentanan tingkat tinggi seperti Kecamatan Koto XI Tarusan, Kecamatan IV Jurai, Kecamatan Batang 
Kapas, Kecamatan Sutera, Kecamatan Ranah Pesisir dan Kecamatan Linggo Sari Baganti. Bahkan di beberapa titik memiliki tingkat kerentanan sangat tinggi seperti di Kecamatan IV Jurai dan Kecamatan Linggo Sari Baganti. Hal ini dikarenakan wilayah tersebut bersifat fully exposed dan tidak memiliki pelindung pantai sehingga mengakibatkan erosi hingga mencapai $65 \%$ selama 10 tahun terakhir, tentunya hal ini akan mempercepat terjadinya kerentanan pesisir Kabupaten Pesisir Selatan hingga masa yang akan datang.

\section{Daftar Pustaka}

[BNPB] Badan Nasional Penanggulangan Bencana. 2019. Katalog desa kelurahan rawan tsunami. BNPB

Alexandrakis, G., Manasakis, C., dan Kampanis, N.A. (2015). Valuating the effects of beach erosion to tourism revenue. A management perspective. Ocean \& Coastal Management, 111, 111

Dhiauddin, R., Gemilang, W.A., dan Wisha, U.J. (2017). Pemetaan kerentanan pesisir Pulau Simeulue dengan metode CVI (coastal vulnerability index). Enviro Scienteae, 13(2), 157-170.

Fuadi, K., dan Yoswaty, D. (2016). Kajian Potensi Ekowisata Bahari Kenagarian Mandeh Kecamatan Koto XI Terusan Kabupaten Pesisir Selatan Provinsi Sumatera Barat. Jurnal Online Mahasiswa (JOM) Bidang Perikanan dan Ilmu Kelautan, 3(2), 1-12.

Gornitz, V. M., White, T.W., dan Daniels, R.C. (1992). A coastal hazards data base for the US East Coast (No. ORNL/CDIAC-45; NDP-043A). Oak Ridge National Lab., TN (United States). Carbon Dioxide Information Analysis Center

Gornitz, V.M., White, T.W., dan Cushman, R. M. (1991). Vulnerability of the US to future sea level rise (No. CONF910780-1). Oak Ridge National Lab., TN (USA).
Jadidi, A., Mostafavi, M.A., Bédard, Y., Long, B., Grenier, E. (2013). Using geospatial business intelligence paradigm to design a multidimensional conceptual model for efficient coastal erosion risk assessment. Journal of coastal conservation, 17(3), 527-543.

Marfai, M.A., dan King, L. (2008). Potential vulnerability implications of coastal inundation due to sea level rise for the coastal zone of Semarang city, Indonesia. Environmental Geology, 54(6), 1235-1245. doi:10.1007/s00254007-0906-4

Özyurt, G. (2007). Vulnerability of coastal areas to sea level rise: a case study on Göksu Delta. Doctoral dissertation. Middle East Technical University

Rosidi, H.M.D., Tjokrosapoetra, S., Pendowo. B., Gafoer, S., and Suharsono. (1996). Peta Geologi Lembar Paninan dan Bagian Timurlaut Lembar Muara Siberut, Sumatera. Bandung. Pusat Penelitian dan Pengembangan Geologi

Rozamuri, M. F., dan Hidayat, R. (2016). Studi Awal Granulometri Pada Sungai Mandeh Dan Sungai Nyalo, Teluk Mandeh, Kabupaten Pesisir Selatan, Sumatera. In Proceeding, Seminar Nasional Kebumian Ke-9 Peran Penelitian Ilmu Kebumian Dalam Pemberdayaan Masyarakat 6-7 Oktober 2016; Graha Sabha Pramana. Departemen Teknik Geologi Ft Ugm.

Sharples C, Mount R, Pedersen T. (2009). The Australian coastal Smartline geomsorphic and stability map version 1: manual and data dictionary. School of Geography \& Environmental Studies, University of Tasmania 8th October 2009 Manual version 1.1 